\title{
1 A guide to using GPS-based tracking to study animal societies
}

Peng He $\mathrm{He}^{1,2,3,4,+\wedge}$, James A. Klarevas-Irby ${ }^{2,3,4,5, \wedge}$, Danai Papageorgiou ${ }^{1,4}$, Eli D. Strauss $^{1,2,4}$, Damien R. Farine $e^{1,4,6, *}$

1Department of Collective Behaviour, Max Planck Institute of Animal Behavior, Konstanz, Germany

${ }^{2}$ Centre for the Advanced Study of Collective Behaviour, University of Konstanz, Konstanz, Germany

${ }^{3}$ Department of Biology, University of Konstanz, Konstanz, Germany

${ }^{4}$ Department of Evolutionary Biology and Environmental Science, University of Zurich, Zurich, Switzerland

${ }^{5}$ Department of Migration, Max Planck Institute of Animal Behavior, Radolfzell, Germany

${ }^{6}$ Division of Ecology and Evolution, Research School of Biology, Australian National University, 46 Sullivans Creek Road, Canberra, ACT 2600, Australia

+peng.he@outlook.de

*damien.farine@ieu.uzh.ch

^authors contributed equally

ORCID:

PH: 0000-0002-7176-701X

JAKI: 0000-0001-7499-4085

DP: 0000-0001-5535-6133

EDS: 0000-0003-3413-1642

DRF: 0000-0003-2208-7613 


\section{ABSTRACT}

GPS-based tracking is a widely used automated data collection method for studying wild animals. Much like traditional observational methods, using GPS devices to study social animals requires making a number of decisions about sampling that can affect the robustness of a study's conclusions. For example, sampling fewer individuals per group across many distinct social groups may not be informative enough for inferring behavioural patterns at a finer social organizational scale, while sampling more individuals per group across fewer groups limits the ability to draw conclusions about populations. Here, we integrate previous insights from animal social network analysis with simulated and empirical data to provide quantitative recommendations when designing GPS-based tracking studies of animal societies. We outline the trade-offs faced by researchers, and how these trade-offs should vary across social organizational scales and social systems in relation to questions of interest, such as those defined within versus among groups, and spanning from cohesive, stable groups through to more open societies. We discuss three fundamental axes of sampling effort requiring consideration when deploying GPS devices to study animal societies: 1) Sampling coverage-the number and allocation of GPS devices among individuals in one or more social groups;

2) Sampling duration - the total amount of time over which devices collect data; 3) Sampling frequency - the temporal resolution at which GPS devices record data. Exploring each axis, we quantify the relationship between sampling effort and sampling error, giving recommendations on GPS sampling design to address research questions across social organizational scales and social systems-from group movement to social network structure and collective decision-making. In doing so, we also highlight practical 
46 limitations on deploying GPS tracking. Our study provides practical advice for empiricists

47 to navigate their decision-making processes when designing GPS-based field studies of

48 animal social behaviours, and highlights the importance of identifying the optimal

49 deployment decisions for drawing informative and robust conclusions.

KEYWORDS 


\section{INTRODUCTION}

Studying animal societies requires collecting both individual-level (what is the animal doing?) and relational (what is the relationship between animals?) data (Altmann 1974; Krause et al. 2013). Prior to data collection, researchers have to make decisions about how to employ finite resources to adequately sample social behaviours. While sampling design is a major consideration across all fields of biology, it is critical when studying social behaviour because the number of possible inter-individual relationships increases exponentially with the study population size (Davis, Crofoot \& Farine 2018). Further, social relations can change rapidly over time (Pinter-Wollman et al. 2014; Gil et al. 2018).

Thus, studying social behaviour generally requires sampling individuals simultaneously, frequently, and over large temporal scales. To achieve these requirements, automated sampling methods are increasingly used (Krause et al. 2013; Nomano et al. 2014; Wilmers et al. 2015; Ferreira et al. 2020; Gupte et al. 2021; Keitt \& Abelson 2021; Shizuka et al. 2021; Smith \& Pinter-Wollman 2021).

One automated method that is becoming increasingly feasible thanks to decreasing costs and better miniaturisation is GPS telemetry. GPS telemetry explicitly captures when and where individual animals go, opening new avenues of research into how animals interact with their social and ecological environment (Cagnacci et al. 2010; Tomkiewicz et al. 2010; Kays et al. 2015; Leu et al. 2016). GPS devices can reduce sampling biases and increase the volume and dimension of data collected relative to human observers (Crofoot 2021). Importantly, GPS devices can be deployed on more individuals than could possibly be observed simultaneously, potentially capturing fine-scale social processes such as group 
movement and collective decision-making (Strandburg-Peshkin et al. 2015). Studies over the last decade have established simultaneous GPS-based tracking as a productive approach for generating new insights into animal social ecology (Dell'Ariccia et al. 2008; Nagy et al. 2010; Lührs \& Kappeler 2013; Strandburg-Peshkin et al. 2015; Leu et al. 2016; Spiegel et al. 2016; Springer et al. 2016; Farine et al. 2017; Papageorgiou et al. 2019; Wielgus et al. 2021). Despite its strengths, GPS tracking is far from being a panacea for challenges related to social data collection. The cost of GPS devices (and data transfer), the challenges of deployment, and technological limitations can all constrain study design.

To effectively apply GPS tracking to study social behaviours, researchers need to tailor sampling design to research questions and social systems. Animal social behaviours span various levels of social organization (Wilson 1975; Aureli et al. 2008; Prox \& Farine 2020), such as how one individual interacts with another, how individuals form groups, how groups themselves interact, and how populations are socially structured (Lukas \& Clutton-Brock 2018; He, Maldonado-Chaparro \& Farine 2019; Kappeler 2019). Optimal GPS study design strategies will depend on the social organizational level under investigation-for example, tracking all individuals in one social group is useful for sampling interactions among group-mates but not among groups. Another important consideration is that some animals associate almost exclusively with the same set of individuals (e.g., within territory boundaries, Bishop \& Groves 1991; Jordan, Cherry \& Manser 2007), whereas others form open societies where group membership and size change frequently (Aureli et al. 2008; Connor \& Krutzen 2015; Farine et al. 2015). By influencing how often individuals are found together, these dynamics shape how GPS tracking can be employed to study social behaviours. 
In this paper, we first outline the common trade-offs faced by researchers using GPS tracking to study animal societies, focusing on three key axes: sampling coverage, sampling duration, and sampling frequency. We then draw insights from previous studies, two whole-group GPS tracking datasets of vulturine guineafowl (Acryllium vulturinum), and simulated data, to provide practical advice for empiricists facing these trade-offs when designing field studies.

\section{KEY TRADE-OFFS IN GPS-BASED STUDIES OF SOCIAL BEHAVIOURS}

Many factors should be considered when designing GPS-based tracking studies of social behaviours (Fig. S1). Among these are ethical and practical limitations when capturing and tagging animals, and ongoing research and development is aimed at understanding and minimizing these limitations (Portugal \& White 2018; Klegarth et al. 2021; Portugal \& White 2021; Wilson et al. 2021). Here, we assume that researchers follow ethical and legal guidelines for deploying GPS devices, and focus on providing guidance on how to deploy devices effectively to optimize data collection for addressing different research questions (Fig. 1). 


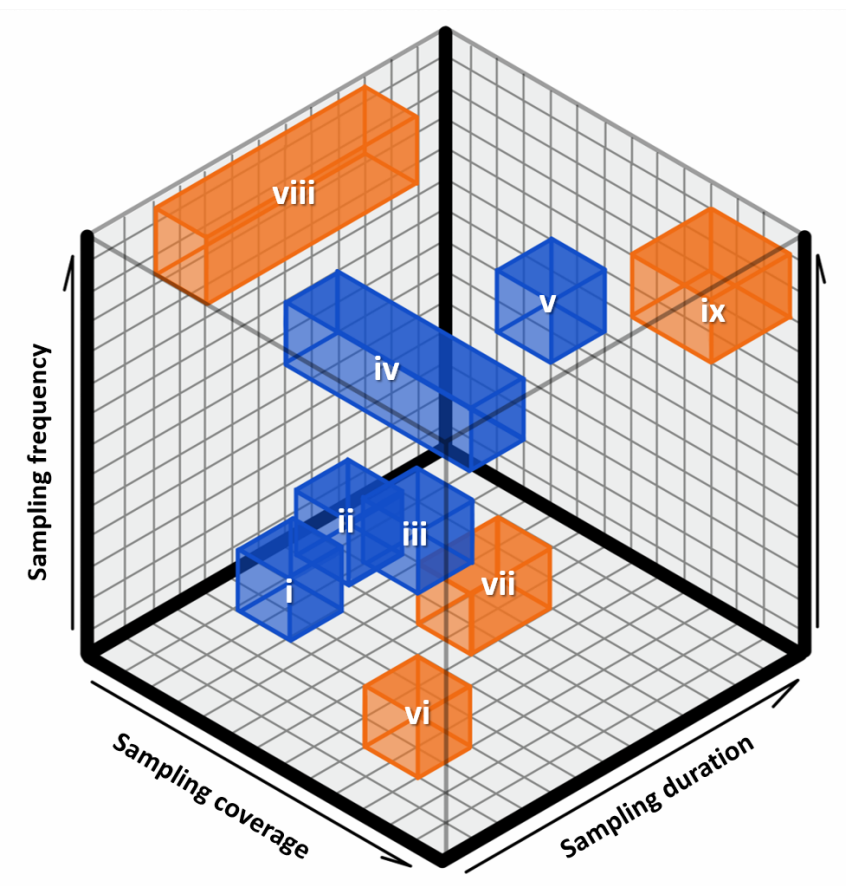
measurements of social behaviour.
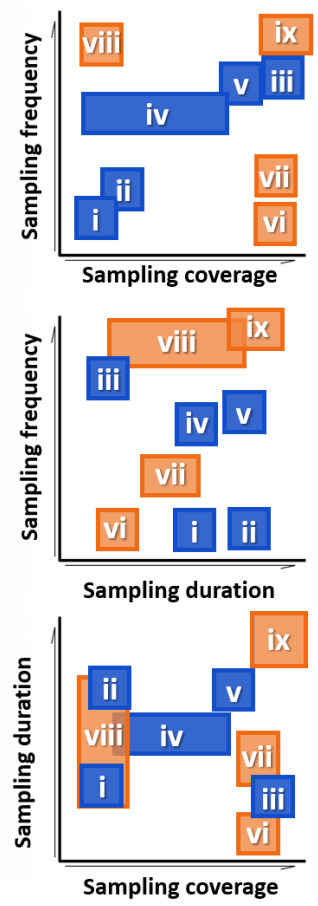

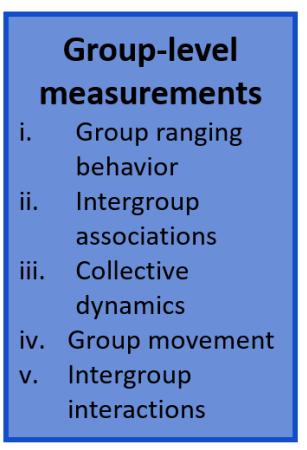

Individual-level measurements

vi. Within-group associations

vii. Interindividual associations (open societies)

viii. Energetics

ix. Social interactions

\section{Fig. 1 Three fundamental dimensions of GPS sampling design when studying} animal societies. The types of questions that can be answered using GPS tracking are broadly governed by three key axes of study design: sampling coverage-the number and distribution of GPS devices throughout a study population, sampling duration-the total amount of time over which devices collect data, and sampling frequency-the temporal resolution at which devices collect data. Social behaviours can typically be thought of as playing out at group (blue boxes) and individual (orange boxes) levels. Within each level, different measurements (i-ix) require differing levels of investment in each axis, and often face trade-offs across axes to capture specific behaviours of interest. This illustration highlights the relative sampling effort across each dimension for different 


\subsection{Sampling coverage}

All GPS-based studies face financial and practical constraints on the number of devices that can be deployed. Having more devices (relative to the study population size) will naturally provide more data for more-robust inferences of social behaviours. However, deploying more devices is not only financially costlier, it can also introduce a number of logistical challenges in terms of data-recovery (see 2.4). Therefore, researchers need to strategically decide how many devices to deploy, and how broadly to distribute them (i.e., 'sampling coverage').

Sampling coverage requirements will depend on the scale of social organization in relation to research questions and whether a study focuses on social structure (e.g., patterns of association or interactions) or processes (e.g., transmission or collective behaviour). Structure-focused questions, such as whether individuals have preferred or avoided social relationships (e.g., Cantor et al. 2012; Best et al. 2014; Gero, Gordon \& Whitehead 2015), require broad, but not necessarily exhaustive, deployments of devices - it is fine to not capture every single pair of associates, as long as a range of association strengths are represented-with the number of devices to be deployed depending on social scale (e.g., group vs population). In terms of allocation, randomly deploying GPS devices to individuals can effectively test for preferred social relationships. Questions addressing larger population-scale structure, such as whether there are distinct social communities within a population (e.g., Shizuka \& Farine 2016), may require distributing GPS devices more broadly to distinguish higher levels of social organisation. 
Process-focused questions require thorough coverage of social relationships, which can be very device-intensive. Without a relatively complete representation of social connections, inference may fail (Wild \& Hoppitt 2019). For example, observing a pathogen spreading from individual $A$ to $B$ to $C$, with edges $A-B$ and $B-C$, would fail to reveal socially-mediated transmission if $A$ and $C$ become infected and $B$ is missing from the study. As such, process-focused questions may need to be studies at smaller scales, where higher proportions of individuals can be tracked, or to focus on interactions among larger social organizational units (e.g., where an entire group can be represented by one device).

\subsection{Sampling duration}

Sampling duration is fundamentally limited by the battery life of GPS devices (Fig. S1). Power is consumed each time a device switches on to collect a point, leading to a major trade-off between the sampling frequency and the longevity of battery life that determines sampling duration. For example, sampling of GPS collars fitted to wild olive baboons (Papio anubis) lasted 15 to 30 days at $1 \mathrm{~Hz}$ (Farine et al. 2017), whereas those fitted to elephants (Loxodanta africana) operate at much lower sampling frequencies but can last many years (Hahn et al. 2022). Some GPS devices can partly overcome this challenge by using solar panels to recharge batteries, by applying programming settings such as using geofencing to spatially vary sampling regimes (Sheppard et al. 2015), or by using acceleration sensors to switch off/on GPS devices when animals are (in)active (Brown et al. 2012). Nevertheless, all studies must strike a balance between sampling frequency and sampling duration. There is increasing awareness that long-term social experiences 
can shape fine-scale social behaviours (Biro, Sasaki \& Portugal 2016; Strauss \& Holekamp 2019). The key consideration is therefore whether a given sampling duration can reveal fine-scale social processes and the long-term factors that govern them.

\subsection{Sampling frequency}

Sampling frequency impacts both battery life and the inferences that can be made from the resulting data. Animal movement is inferred from sequential fixes, so the more continuously fixes are collected, the more complete the information is about where the individual has been and, potentially, what it has been doing (Wang 2019). In most vertebrates, sampling frequency at $1 \mathrm{~Hz}$ (one GPS fix per second) captures complete information about where individuals have moved and how (Ryan et al. 2004). However, such high sampling frequencies are energetically demanding, with serious implications for sampling duration. Thus, most studies opt for lower sampling frequencies to save battery life. Studies have collected 10 fixes every 5 minutes (e.g., vulturine guineafowl, Papageorgiou et al. 2019), 1 fix every 30 minutes (e.g., swamp wallabies Wallabia bicolor, Fischer et al. 2018), or 1 fix every hour or more (e.g., African elephants, Wittemyer et al. 2008). However, lower sampling frequencies come at a substantial cost in terms of accurately capturing individuals' behaviour. For example, estimates of travel distances are heavily influenced by sampling frequency, often only reaching realistic measures with sub-minute sampling intervals (Rowcliffe et al. 2012). In some cases, intermediate locations (i.e., an animal's position in the time between fixes) can be inferred using spatial interpolation (Strandburg-Peshkin et al. 2015; Hirakawa et al. 2018), smoothing spline models (Whetten 2021), or the dead reckoning technique (Dewhirst et al. 2016). It should 
also be noted that battery consumption does not scale linearly with increasing sampling frequency. GPS devices use energy each time they (re)boot and search for satellites, which takes longer with sparser sampling regimes, meaning that the same battery charge collects fewer data points at longer sampling intervals. Device typically do not switch off during more intensive regimes. For example, $0.2-0.5 \mathrm{~Hz}$ may use as much battery as 1 $\mathrm{Hz}$ (but $1 \mathrm{~Hz}$ may have greater battery costs for data transfer).

\subsection{Further practical considerations}

A few other practical issues (Fig. S1) are worth considering. For example, social interactions can take place at small spatial scales (i.e., $<1 \mathrm{~m}$, see 3.1), so in such cases GPS accuracy is particularly important. Sampling while consistently keeping GPS devices switched on will typically produce more accurate estimates of positions, because devices can reuse satellite information from previous fixes (eObs $\mathrm{GmbH}$, pers. comm.). Switching off devices between consecutive fixes will generally result in lower accuracy, especially when the gaps are long (e.g., a few hours). Habitat density (e.g., forest canopies vs open savanna) will impact GPS precision because of interference during satellite detection.

Researchers also need to consider data retrieval, which can become cumbersome when deploying many devices simultaneously. Deploying more devices will increase costs if data are retrieved via mobile phone networks, download time if data are retrieved via radio download, or retrapping/relocation effort if data is retrieved by recovering devices. Device data storage capacity may require frequent data retrieval, and missed data 
downloads can lead to data loss (e.g., Strandburg-Peshkin et al. 2015 retrieved GPS data nightly to avoid data loss; see also Box 1).

\section{SOCIAL NETWORK STRUCTURES}

Animal social networks are often assembled from social associations or interactions (Whitehead 2008; Farine 2015; Farine \& Whitehead 2015; Krause et al. 2015), both of which can be inferred from GPS data. In GPS tracking studies, social associations are defined by co-location of individuals, while interactions can be inferred when individuals have a detectable impact on the behaviour of others (e.g., one individual displacing another). Several studies have suggested that social networks are quite robust to sampling subsets of the population, so GPS devices can be strategically deployed to characterize even large social networks. Specifically, Silk et al. (2015) estimated that studies sampling $30 \%$ or more of a population can generate reliable estimates of individuals' social network positions. Subsequent studies highlighted that repeated sampling and avoiding misidentifications are critical for producing accurate networks (Davis, Crofoot \& Farine 2018; Sunga, Webber \& Broders 2021)—both are the strengths of GPS tracking data.

\subsection{Estimating social associations}

Associations can be defined by applying spatiotemporal co-location rules to individuals' GPS fixes. A common approach is to set a distance threshold under which individuals are considered associated. Thresholds should consider the biology of the study organisms 
and, particularly for smaller animals, the precision of GPS devices. For example, Godfrey et al. (2014) constructed an undirected association network describing the patterns of associations among 60 Australian sleepy lizards (Tiliqua rugosa) using synchronous GPS fixes recorded every $10 \mathrm{~min}$ and a co-location rule where individuals were assumed to be socially associated when the GPS registered the individuals as within $14 \mathrm{~m}$ of each other. This threshold was derived from the observation that lizards within $2 \mathrm{~m}$ of each other were likely to make social contact, combined with a median GPS precision of $6 \mathrm{~m}$. Such distance thresholds can be chosen based upon traditional observation of the study organism, through data-driven studies of these thresholds (Haddadi et al. 2011), or by using statistical approaches (Papageorgiou et al. 2019).

A simple approach to defining an association threshold is to interrogate the distribution of inter-individual distances and extract the first mode, which likely represents individuals that are socially associating. In larger groups, associations can be defined following a chain rule, where all individuals that form part of a connected component are considered as being associated (e.g., if $A-B$ and $B-C$, then $A-C$ even if $A$ and $C$ are beyond the threshold). There are also tools (Ansari et al. 2020) for identifying clusters of GPS fixes to infer behavioural events or states (e.g., kills by predators or behavioural activity states). However, few have been extended to detect clustered social associations (i.e., inferring the presence of social aggregations) across time (but see Kalnis, Mamoulis \& Bakiras 2005). 


\subsection{Inferring social interactions}

An emerging application of GPS tracking is to infer social interactions among individuals. Unlike associations, which are readily characterised at low sampling frequencies, interactions require simultaneous high-frequency data (e.g., $1 \mathrm{~Hz}$ ). This is because inference is drawn from relative movements at fine spatiotemporal scales, rather than proximity alone. For example, dominance interactions can be detected from approachavoid interactions (A approaches B and B moves away) and chases (Strandburg-Peshkin et al. 2015). Thus, studying social interactions requires sequential detections collected simultaneously across individuals. The ability to detect interactions from GPS tracking data will also depend on the spatial scale over which they occur relative to GPS error. For example, a GPS error within $1 \mathrm{~m}$ allows for detections of displacements that occur over tens of meters in baboons (e.g., Strandburg-Peshkin et al. 2015), but make it more challenging to detect those that take place within a meter or less, as in the vulturine guineafowl (Dehnen et al. 2022). Furthermore, GPS tracking is perhaps best-suited to detecting extreme interactions (e.g., chases), while many other interactions (e.g., vocal interactions, allogrooming) cannot be detected from spatial positions alone. If extreme interactions are non-randomly distributed among individuals (e.g., Dehnen et al. 2022), the resulting networks may be biased. These issues aside, detecting interactions is achievable. Finally, we note that inferred interactions should be verified by traditional observations (e.g., by making videos of the GPS data), while it should be feasible to extend machine learning approaches for detecting patterns in temporal data to extract interactions from GPS trajectories. 


\subsection{Constructing social networks}

Whereas association events or interactions can be inferred from singular snapshots of spatial positions, social relationships between individuals are typically quantified from the tendency for individuals to associate or interact over (observation) time. The simple ratio index (SRI) defined as the number of observations of two individuals together divided by the total number of observations involving either of them (Hoppitt \& Farine 2018), is commonly used to calculate relationship strength. However, this SRI formula needs to be modified for GPS data, as an observation of individual A without individual B is only informative if $B$ is confirmed elsewhere (i.e. both $A$ and $B$ have a data point, either together or apart). Therefore, the denominator of the formula should only include observations where GPS data are simultaneously available for both individuals.

The trade-off between sampling frequency and sampling duration is critical in GPS-based social network studies. High sampling frequencies (e.g., $1 \mathrm{~Hz}$ ) are robust in capturing how association events or interactions change from one time point to the next (Hobson, Avery \& Wright 2013; Farine 2018). However, substantial data under high sampling frequency in short periods can create a false sense of certainty when defining relationships, which play out over months or years (e.g., spanning inter-reproductive periods). Lower sampling frequencies (e.g., every hour) will fail to capture the moment-by-moment dynamics of social associations or interactions, but may be better at capturing how relationships change (or not) over time. Both the changes in associations or interactions and the changes in relationship strengths can be studied using dynamic networks, but represent different dimensions of social behaviours. 


\section{SOCIAL BEHAVIOURS WITHIN GROUPS}

In cohesive groups, the spatial behaviours of group members are typically shaped by those of others (Farine et al. 2017). However, it remains unclear how GPS coverage within a social group (which is often the foremost consideration when designing a study) affects the inferences made about individuals' spatial position in their group and the spatial properties of groups (Fig. 2). To address this gap, we evaluated how sub-sampling influences inferences of individual and group spatial behaviours (see 4.1 and 5.1, respectively), using GPS tracking and simulated data (see Box 1 for methods).
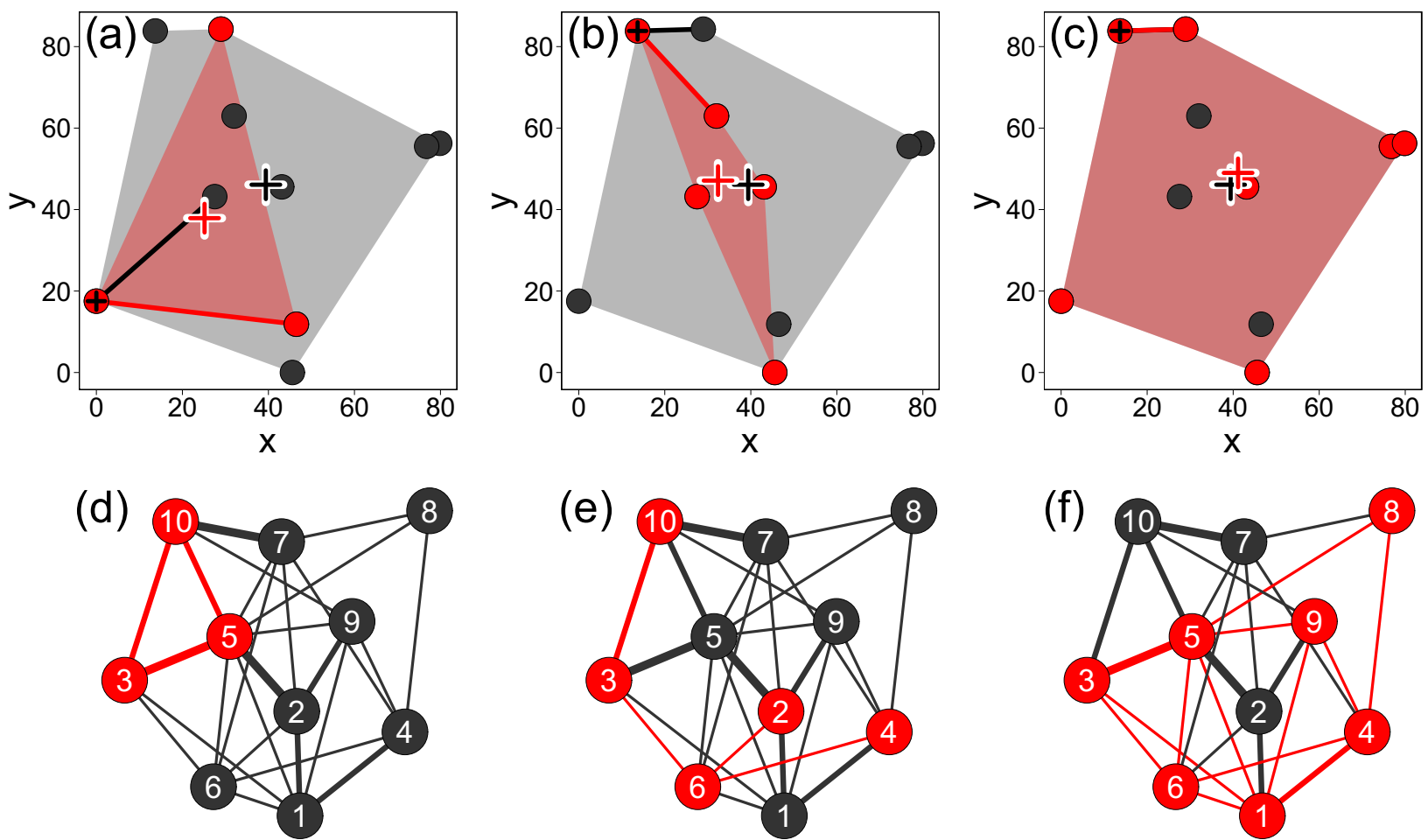

Fig. 2 An illustration of the effects sub-sampling on estimates of individual- and group-level properties. Deploying GPS devices on a subset of group members 
(black=all group members, red=sampled individuals) can impact behavioural measures. At the individual-level, subsampling influences the accuracy of estimates in the identity of, and distance to, the nearest neighbours (e.g., red focal individuals marked with a cross in a-c as members in smaller subsamples have different nearest neighbours and larger nearest neighbour distances); at the group-level, subsampling influences the accuracy of estimates in group spatial coverage (i.e., MCP, the minimum convex polygons, a-c) and the geometric centroid of the spatial positions of individuals (large bold crosses, a-c). Subsampling can eventually influence inferences on social association network structures (d-f, corresponding to $a-c)$.

\subsection{Estimating individuals' spatial positions within groups}

Individuals' spatial positions relative to other group members can influence vulnerability to predation (Barta, Flynn \& Giraldeau 1997), foraging competition with group-mates (Gall \& Manser 2018), or availability to receive information from social partners (Rosenthal et al. 2015). When inferring such positions, there is a trade-off between the accuracy of estimates and sampling coverage. Increasing the proportion of tracked individuals results in exponential decreases in error of estimates of distance to nearest neighbour and spatial centrality (surroundedness) (Fig. 3). Both empirical and simulated data suggest that, regardless of group sizes, studies can miss up to half of the individuals in a group while still being able to make accurate estimates of nearest-neighbour distances (i.e., median error $<1 \mathrm{~m}$ when $50 \%$ tracked, Fig. $3-\mathrm{a}$, i-iii). While error sizes are generally small, it is worth noting that any non-zero error would also result in mis-assignment of the identities of such neighbours (Fig. 2; the chance of mis-assignment is the same as the proportion 


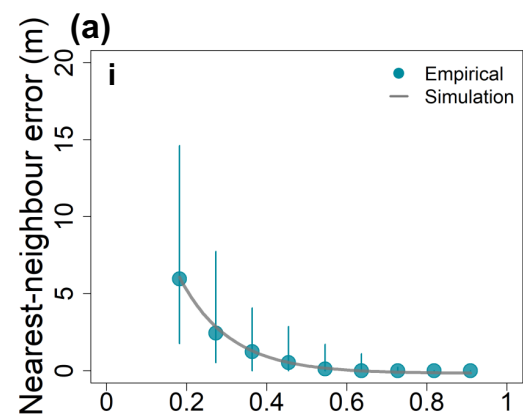

(b)

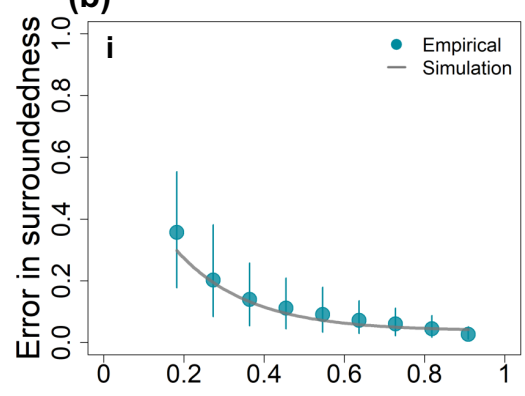

332 necessary in larger groups.

of non-tracked individuals in groups). For surroundedness (Fig. 3-b, i-iii), reliably accurate estimates require a larger proportion $(\geq 60 \%)$ of a group to be GPS-tracked, especially in smaller groups (Fig. 3-b i,iii). The relationship between GPS coverage and error is well captured by an exponential curve (see Table S1). In all cases, lower GPS coverage is


\section{Fig. 3 Error in estimates of the nearest-neighbour distance (a) and surroundness}

(b) decrease exponentially with increasing GPS coverage. (i-ii) Tracking data from two vulturine guineafowl groups (i: $N=11$; ii: $N=25$ ) randomly subsampled to explore the effects of GPS coverage on estimates of individuals' spatial positions in groups. Points represent the median error of estimates from the subsampled empirical data, with vertical bars showing the $1^{\text {st }}$ and $3^{\text {rd }}$ quartiles of errors. Curves represent the predicted median error of estimates from exponential models (Table S1) fitted to simulated data matching 
the spatial extents and group sizes in empirical data. (iii) Curves showing the exponential relationship between GPS coverage and error drawn from simulated data with varying group sizes (Table S2).

\subsection{Collective movement and decision-making}

A typical characteristic of group-living animals is the emergence of collective behaviours (Sumpter 2006). For instance, groups of fish engage in collective schooling behaviour to reduce predation risk to any individual (Herbert-Read et al. 2017), whereas griffon vultures (Gyps fulvus) forage in a 'sky network' where individuals learn about available food sources by observing the behaviour of their neighbours (Cortés-Avizanda et al. 2014). Studying collective behaviours requires perhaps the greatest observational effort (Strandburg-Peshkin et al. 2015; Hughey et al. 2018), comprising high-spatiotemporalresolution movement data (high sampling frequency) and high GPS coverage in order to capture the transient socio-spatial dynamics that produce collective outcomes. To date, most studies have been conducted in semi-wild systems, such as homing pigeons (Pettit et al. 2013; Sankey et al. 2021), where individuals can be easily recaptured to apply and remove GPS devices. However, the limitations of sampling frequency can be overcome by focussing sampling effort to discrete periods to maximize the collection of simultaneous high-resolution data. For example, solar-powered GPS devices on vulturine guineafowl are given three days to recharge so that all devices have full batteries to collect high-resolution at the same time every fourth day (Box 2). 


\section{BEHAVIORS AMONG GROUPS}

Assessing behaviours at the group level can reveal inter-group behavioural variability and the influences that groups exert on each other. One prominent way in which groups vary is in their movement characteristics-for instance, meerkat groups emerge from their burrows at different times of day (Thornton, Samson \& Clutton-Brock 2010), and vulturine guineafowl groups differ in home range size and daily travel distance (Papageorgiou \& Farine 2020a). Most simply, the behaviour of a group (or groups) can be inferred from a GPS-tracked group member (Papageorgiou \& Farine 2020a; Papageorgiou et al. 2021). This can, for example, capture how groups interact with each other, for instance via intergroup social interactions (Crofoot et al. 2008; Papageorgiou et al. 2019) or dispersing individuals (Alberts \& Altmann 1995; Armansin et al. 2020; Klarevas-Irby, Wikelski \& Farine 2021). However, there is currently little guidance on how many GPS-tracked individuals are required to characterise other group-level properties. Metrics such as the precise location of the group (e.g., for habitat selection of groups) or the level of spatial dispersion of group members (e.g., as an indirect measure of risks) will be more precise as more individuals are tracked. Further, studying behaviours such as inter-group interactions or associations-which are substantially rarer than within-group interactions (e.g., when only a small proportion of individuals in each group infrequently interact or associate with others from different groups)—will generally require deploying more GPS devices per group (Box 2) and increasing GPS sampling duration. 


\subsection{Behavioural characteristics of groups}

Group location (i.e., the geometric centroid of all individuals) and spatial dispersion (i.e., the total area covered by a group) are fundamental metrics characterizing group-level behavioural patterns. Using both empirical and simulated data (Box 1), we find that estimating the precise location of cohesive groups is relatively robust to low GPS coverage. In vulturine guineafowl, as few as two tagged individuals can estimate a group's centroid with $<5 \mathrm{~m}$ of error (Fig. $4-\mathrm{a}$, i-ii), which is small given that groups can travel up to 10kms per day (Papageorgiou et al. 2021). For both simulated and empirical data, the relationship between GPS coverage and centroid estimation error follows a negative exponential relationship (Fig. 4a). As such, unless extremely precise locational information is needed, the spatial location of groups can be sufficiently estimated with as few as 1-3 devices per group, regardless of group size. By contrast, estimating a group's spatial dispersion [e.g., the area of a minimum convex polygon (MCP) containing all group members] requires the majority of the group to be marked, especially in smaller groups (Fig. 4-b, i-iii). Even with very high GPS coverage (e.g., >80\%), measures often underestimated the dispersion of the group by $20 \%$ or more. The relationship between GPS coverage and spatial dispersion error is well captured by a negative exponential function (Fig. 4b). 


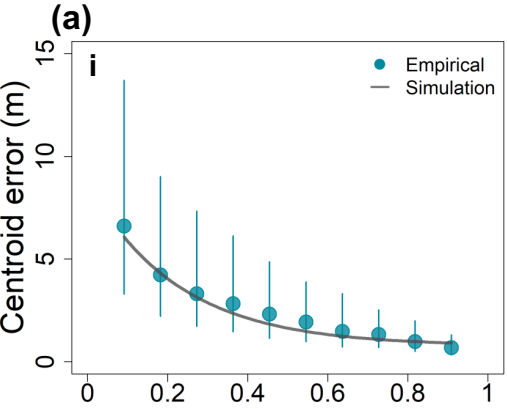

(b)

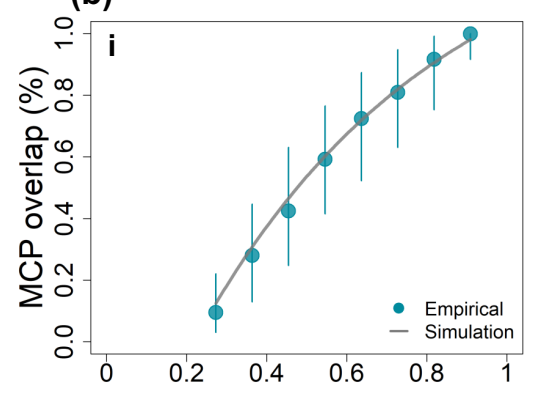

398 group sizes (Table S2).
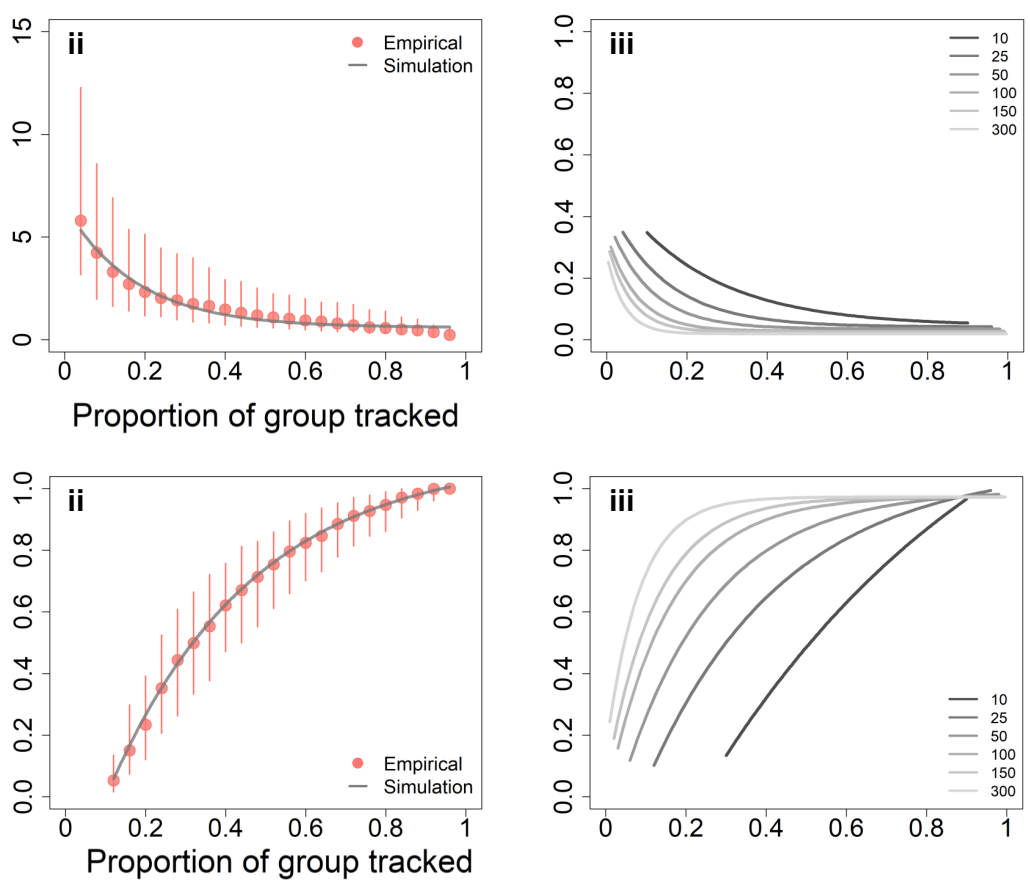

Fig. 4 Error in estimates of group centroid (a) and spatial dispersion (b) decrease exponentially with GPS coverage. (i-ii) Tracking data from two vulturine guineafowl groups (i: $N=11 ; i: N=25$ ) and simulated data randomly subsampled to explore the effects of GPS coverage on estimates of group position and dispersion. Points represent the median error of estimates from the subsampled empirical data, with vertical bars showing the $1^{\text {st }}$ and $3^{\text {rd }}$ quartiles of errors. Curves represent the predicted median error of estimates from exponential models (Table S1) fitted to simulated data matching the spatial extents and group sizes in empirical data. (iii) Curves showing the exponential relationship between GPS coverage and error drawn from simulated data with varying 


\subsection{Inter-group relationships}

Groups influence each other through the dispersal of individuals (Alberts \& Altmann 1995; Bond et al. 2021), associations between groups (Qi et al. 2014; Papageorgiou et al. 2019; Henriquez et al. 2021), or agonistic interactions (Thompson et al. 2017; Dyble et al. 2019). Studying dispersal requires deploying GPS devices to both dispersers and to the groups that these dispersers might move between. In such cases, a single tagged resident individual in each group is likely to be sufficiently informative if group membership is highly stable. Studying intergroup associations follows the same principles as studying associations among individuals (see 3.1), where the unit of focus (i.e., groups) can be meaningfully represented by a single individual if the scale over which groups are spread is small relative to the space over which groups move. Finally, while studying agonistic interactions among groups broadly follows the same principles as studying interactions among individuals, there may be additional challenges. Groups may detect each other over large distances and be more likely to passively avoid interactions (e.g., through scent marking; Christensen et al. 2016), leaving the spatial scale at which groups interact unclear. Further, not all individuals might contribute equally to inter-group interactions, meaning that consideration should be put regarding who to deploy GPS devices onto. 


\section{SOME STRATEGIC CONSIDERATIONS}

Besides the constraints outlined above, several other factors should be considered when deploying GPS devices to study social behaviour. Below we list and discuss a few of these, and in Box 2 we outline how we deployed GPS devices and programmed these to achieve the multiple aims of our vulturine guineafowl project.

\subsection{Redundancy}

In most cases, studies should consider tracking extra individuals in each group beyond the minimum required for the study design. For example, while the locations of each cohesive social group might be captured by a single group member, its GPS device could fail or the individual could die. Further, when using mixed GPS sampling strategies (see 6.3), having multiple individuals in each group can maximise the probability of at least one individual collecting higher resolution data.

\subsection{Partitioning sampling effort in time}

It can be useful to vary GPS sampling across time to focus data collection on certain time windows over others. For example, diurnal species are largely inactive at night (Isbell et al. 2017; but see Loftus et al. 2021), meaning that GPS devices are often switched off at night to conserve battery. It can also be worthwhile to program devices to increase sampling frequency during periods when animals are more active (e.g., morning and/or evening), or decrease sampling frequency during seasons when conditions are less optimal for data collection (e.g., during breeding seasons, Box 2). However, when doing 
so, it is worth considering whether partitioning sampling in time could introduce biases or result in incorrect inferences.

\subsection{Mixed GPS sampling frequencies}

The major trade-off is between sampling frequency and sampling duration. Even with solar-powered GPS devices, the capacity to collect high-resolution data across entire days is limited (Box 2). A solution to this is to use a mixture of sampling regimes-having some individuals deployed to prioritise shorter bursts of higher sampling frequencies and some individuals prioritised to capture long-term sampling. With solar-powered devices, it is often possible to programme devices to switch from low- to high-resolution as the battery charges (Box 2). Such an approach can allow devices to work in a collaborative way.

\subsection{Supplementing GPS tracking with other observational data}

A key limitation of GPS tracking data for inferring social behaviours is that observers are blind to the absence/presence of untracked individuals in close spatial proximity. GPS tracking studies can therefore benefit from supplementary observational data (Smith \& Pinter-Wollman 2021). Behavioural patterns revealed by observational data can be the ground-truth to those inferred with GPS tracking data, and can be used to evaluate the extent to which data derived from a given deployment of GPS sampling are able to capture true behavioural patterns in animal societies. However, integrating GPS and non- 
GPS data into the same analysis introduces data compatibility challenges, and approaches for harmonizing such datasets warrant further development.

\subsection{Combining GPS data with other sensors}

Modern GPS tracking studies use additional sensors (Williams et al. 2020), such as accelerometers, gyrometers (Marin 2020), heart rate monitors, or body temperature loggers (e.g., Linek et al. 2021). Such data can substantially increase the dimensions of information researchers can retrieve about animals' behaviours (e.g., Harel, Loftus \& Crofoot 2021). Movement-related sensors can improve data on trajectories by allowing tracks between GPS fixes to be reconstructed using dead reckoning (Wensveen, Thomas \& Miller 2015). This can effectively increase sampling frequency with minimal additional battery consumption.

In a social context, acceleration data could be useful when inferring dyadic social interactions such as inter-individual displacements (Strandburg-Peshkin et al. 2015), individual behavioural states (Chimienti et al. 2016), or behavioural synchrony among individuals (Strauss et al. 2021). Further, information about environmental contexts social animals experience could also be inferred from the GPS devices themselves, such as measuring solar exposure (e.g., whether an animal is under cover or not) from changes in GPS battery voltage in solar-powered devices. However, additional sensors increase battery consumption (albeit often a lot less than the GPS sensor itself), and can substantially increase the cost of data storage, retrieval, and management, especially in large-scale studies (Box 2). Furthermore, although some devices come with multiple sensors onboard (e.g., combined GPS sensor and accelerometer), others might require 
487 integrating a separate device along with the GPS device. This can be physically challenging (e.g., there may not be room for a second sensor or device, or exceed weight limits), and for studies requiring synchronization between data streams, communication must be established between the devices or sensors.

\section{CONCLUDING REMARKS}

GPS tracking is a powerful tool for studying social behaviour, but studies face many tradeoffs. Drawing from previous studies, and new empirical and simulated data, we have illustrated how sampling coverage, sampling duration, and sampling frequency can be optimised to address different research questions. For example, many social measuresof individuals within groups (e.g., spatial position) or of groups themselves (e.g., centroids)—can be reliably estimated by tracking relatively few group members. Other measures, such as social interactions among individuals, social processes, or the spatial dispersion of groups, require more intensive sampling frequencies or greater coverage of individuals. We caution against aiming to sample at the highest frequency possible at the cost of sampling duration, and instead suggest that most studies of social behaviour will benefit from prioritising stratified sampling over a longer duration. A good rule of thumb is to sample at the lowest frequency possible that still captures the behaviours under study (e.g., the majority of GPS devices deployed to guineafowl are programmed with the population regime, Box 2). Although our discussion here has focused on cohesive groups, such rules may also apply in non-cohesive groups. However, open societies with fluctuating group membership and size present a different challenge for GPS-based 
510 at the group level are likely to be relevant for whole populations. In general, while there

511 are multiple trade-offs involved at the same time when designing GPS-based studies,

512 there are likely to be optimal sampling strategies to suit most research questions. 
Box 1. Our empirical data is drawn from two social groups of vulturine guineafowl $(\mathrm{N}=$ 11 and $\mathrm{N}=25$ ) in which all members were simultaneously tracked. We randomly selected 100 time stamps from the tracking data, spanning several months, from each group. At each time stamp, the data were subsampled by randomly removing group members [producing groups of size 1 to $(\mathrm{N}-1)$ ], with each level of sub-sampling repeated 10 times (i.e., producing 10 combinations of subsampled individuals for each time stamp). We then extracted four spatial measures describing individual positions and group properties: the distance from some focal individual to its nearest neighbour (a common measure of social association), the spatial centrality of a focal individual within the group (i.e., 'surroundedness', or $1-\mathrm{CV}$, where $\mathrm{CV}$ is the circular variance of the vectors pointing to the focal individual; see Christman \& Lewis 2005 for CV), the spatial position of the entire group (the geometric centroid of all sampled individuals' positions), and the spatial spread of the group [represented by the area of the minimal convex polygon (MCP) containing all sampled individuals]. The effect of sub-sampling on each measure was quantified as the error between the "true" value derived from the full group data and the "observed" value derived from the subsampled individuals only. For nearest-neighbour distance and centroid, the error was defined as the point-to-point distance from the true position (of the spatially-nearest neighbour or the original centroid, respectively) to the observed position (of the nearest remaining neighbour or the new centroid). Error in surroundedness was defined as the difference between the true and observed circular variance for some focal individual included in the subsampled group. Error in group spread was defined as the percent overlap between the MCPs of the subsampled and original group. 
We then simulated data to confirm the relationships between GPS coverage and error. First, for each time stamp in the empirical data, we simulated empirically derived groups $(\mathrm{N}=11$ and $\mathrm{N}=25)$, where simulated individuals' $\mathrm{X}$ and $\mathrm{Y}$ coordinates were drawn from a uniform distribution with the same spatial boundaries as the empirical snapshot. We simulated 100 empirically derived group observations to match each time stamp in the empirical data, and subsampled and measured these following the same procedure as empirical groups.

Second, to examine the general effects of GPS coverage on the accuracy of individualand group-level behavioural estimates, we complemented our empirical dataset and empirically-informed simulations with purely simulated groups varying in size from 10 to 300. Here, $X$ and $Y$ coordinates were drawn from uniform distributions between 0 and 1. We simulated 100 group observations for each group size, which were subsampled and measured following the same procedure as empirical groups. 
Box 2. The GPS-based vulturine guineafowl project was established at Mpala Research Centre in central Kenya in 2016 to study social dynamics within and across groups, at timescales spanning from moment-by-moment movement to lifetime ranging. A pilot study on group membership of a small number of colour-banded individuals and five GPStracked birds ( $15 \mathrm{~g}$, solar-powered devices, e-obs Digital Telemetry, Grünwald, Germany) showed that group compositions and sizes were highly consistent. The study also confirmed the advantages of using solar-powered GPS devices in an equatorial savannah environment-solar conditions there allow for consistent GPS sampling throughout the year from 06:00 to 19:00. Subsequently, more solar-powered GPS devices were deployed to individuals both within and across groups. Specifically, we tracked 2-3 birds per group but distributing sampling effort across as many groups as possible (eventually with a coverage of an entire population consisting of $>20$ groups). GPS sampling effort was designed to prioritise population-level behavioural patterns, by programming the devices to switch on for a 10-second sampling window every 5 minutes (i.e., the 'Population regime', Table 1). A burst of 10 fixes optimizes accuracy of GPS fixes as the battery costs per fix are minimal, and later fixes in each burst are generally more accurate because satellite coverage (i.e., the number of satellites communicating with the device) increases over the time the devices remain on. To take advantage of solar power, devices were programmed to sample at high frequency (i.e., $1 \mathrm{~Hz}$ sampling for 15 minutes at a time) when battery charge was high. Every bird in each group was also colour-banded to facilitate visual identification, regardless of whether they were GPS tagged or not. Combining twice-weekly observations field observations of group membership and size with our population-level GPS data shed light on the underlying patterns of social 
associations among individuals (both within and across groups), revealing the multilevel social structure of the whole population (Papageorgiou et al. 2019). Over time, continued measurements further revealed how group size affects movement and ranging (Papageorgiou \& Farine, 2020a) and how groups use the landscape across seasons (Papageorgiou et al. 2021).

Under the population-level sampling regime (Table 1), devices collect data at high sampling frequency approximately $25 \%$ of the time, suggesting that it is feasible to collect extensive movement data with high temporal resolution. However, variation in battery charge can lead to asynchrony across devices. To study within-group social dynamics (e.g., how groups make decisions), every bird in each of two focal groups (Box 1) was GPS-tracked and devices were programmed to collect data on the same day, every fourth day, spending the intervening days recharging (except for two birds in each group with devices programmed with the population regime to track daily ranging). This 'high-res' regime (Table 1) ensures that all devices collect $>6 \mathrm{~h}$ of synchronous, fine-temporal-scale movement data of all individuals on each operating day. Such data have supplemented observational data to infer how individuals respond to group decisions (Papageorgiou \& Farine 2020b), and to characterise other aspects of group behaviour, as in this study.

Field observations revealed that males are philopatric while females disperse. Thus, devices were primarily deployed onto males for long-term data collection. As some adult females bred, GPS devices were also deployed to these females for opportunities to find nests and to study incubation behaviours. However, the batteries of devices deployed on these breeding females often struggled to maintain an adequate charge due to poor solar 
conditions-incubating birds can stay under dense vegetation for up to 25 days at a time (Nyaguthii 2021). We benefited from the ability to remotely program devices—reducing sampling frequency to one fix per 15 minutes ensured the capacity of batteries to cover the whole incubation period. To study dispersal behaviours, subadult females were GPStracked (Klarevas-Irby, Wikelski \& Farine 2021). In this case, new devices were deployed to ensure maximum battery power (sampling at high frequency covering ca. $30 \%$ of the time in a day). Comparing fine-scale movements of dispersers with residents relied heavily on the ability to have at least one device in each group sampling at high frequency at any time (facilitated by having multiple tagged individuals per group).

Overall, the project has had as many as 121 simultaneously GPS-tracked birds, and many challenges have arisen in project maintenance and data management. For example, each device produces ca. $500 \mathrm{MB}$ of tracking data approximately every 10 days, that requires up to $4 \mathrm{~h}$ of downloading time every second day. This is in addition to extensive effort and time needed to regularly check and maintain deployed devices, and to recover devices when individuals are predated. To partially address these challenges, the accelerometer sensors integrated into our devices have been turned off, as the resulting data streams would prove infeasibly large for our current download regime (but the devices can be reprogrammed for collecting acceleration data if desired). 


\begin{tabular}{|c|c|c|c|}
\hline & Population & Group & Individual \\
\hline $\begin{array}{l}\text { Sampling } \\
\text { coverage }\end{array}$ & $\begin{array}{c}1-6 \text { individuals per group, } \\
\text { averaging } 1 \text { device per } 10 \text { group } \\
\text { members }\end{array}$ & All individuals in a group & $\begin{array}{l}\text { Individuals of interest } \\
\text { (e.g., subadult } \\
\text { females, incubating } \\
\text { females) }\end{array}$ \\
\hline $\begin{array}{l}\text { Sampling } \\
\text { duration }\end{array}$ & $\begin{array}{l}\text { Prioritise long-term (lifetime of } \\
\text { individuals) }\end{array}$ & Medium-term (seasonal) & $\begin{array}{l}\text { Focused (e.g., } \\
\text { breeding season, } \\
\text { dispersal period) }\end{array}$ \\
\hline \multirow{3}{*}{$\begin{array}{l}\text { Sampling } \\
\text { frequency }\end{array}$} & $\begin{array}{l}\text { Population regime (every day): } \\
\text { Highest battery charge: } 1 \mathrm{~Hz}\end{array}$ & $\frac{\text { High-res regime }}{4^{\text {th }} \text { day): }}$ (every & $\begin{array}{c}\text { Specific regimes, } \\
\text { e.g.: }\end{array}$ \\
\hline & $\begin{array}{c}\text { Medium battery charge: } 10 \text { fixes } \\
\text { every } 5^{\text {th }} \text { minute }\end{array}$ & \multirow{2}{*}{$\begin{array}{c}1 \mathrm{~Hz} \text { from } 06: 00 \text { until } \\
\text { battery depletes, and } 2 \\
\text { birds per group following } \\
\text { the population regime }\end{array}$} & $\begin{array}{l}\text { Dispersal: population } \\
\text { regime }\end{array}$ \\
\hline & $\begin{array}{c}\text { Low battery charge: } 1 \text { fix every } 15^{\text {th }} \\
\text { minute }\end{array}$ & & $\begin{array}{l}\text { Breeding: } 1 \text { fix every } \\
15^{\text {th }} \text { minute }\end{array}$ \\
\hline
\end{tabular}




\section{ACKNOWLEDGEMENTS}

We thank the e-obs $\mathrm{GmbH}$ for technical advice on GPS battery life management, the vulturine guineafowl field team coordinated by Brendah Nyaguthii in Kenya. Data were collected with permission from, and in collaboration with, the Kenya National Science and Technology Council, the National Environment Management Authority, the Kenya Wildlife Service, the National Museums of Kenya, Peter Njoroge, the Mpala Research Center. Ethical approval was granted by the Max Planck Society's Ethikrat Committee. This study was funded by a grant from the European Research Council (ERC) under the European Union's Horizon 2020 research and innovation programme (grant agreement No. 850859), an Eccellenza Professorship Grant of the Swiss National Science Foundation (Grant Number PCEFP3_187058) awarded to DRF, and the Max Planck Society. PH, JAKI, and DP acknowledge support from International Max Planck Research School (IMPRS) for Organismal Biology. EDS was funded by the Alexander von Humboldt foundation.

\section{AUTHORS' CONTRIBUTIONS}

$\mathrm{PH}, \mathrm{JAKI}$ and DRF conceptualized the study. PH and JAKI conducted the analyses. PH drafted the manuscript and all authors contributed critically to the revisions and gave approval for publication. 


\section{REFERENCES}

Alberts, S.C. \& Altmann, J. (1995) Balancing Costs and Opportunities - Dispersal in Male Baboons. American Naturalist, 145, 279-306.

Altmann, J. (1974) Observational Study of Behavior - Sampling Methods. Behaviour, 49, 227-267.

Ansari, M.Y., Ahmad, A., Khan, S.S., Bhushan, G. \& Mainuddin (2020) Spatiotemporal clustering: a review. Artificial Intelligence Review, 53, 2381-2423.

Armansin, N.C., Stow, A.J., Cantor, M., Leu, S.T., Klarevas-Irby, J.A., Chariton, A.A. \& Farine, D.R. (2020) Social barriers in ecological landscapes: the social resistance hypothesis. Trends in Ecology \& Evolution, 35, 137-148.

Aureli, F., Schaffner, C.M., Boesch, C., Bearder, S.K., Call, J., Chapman, C.A., Connor, R., Di Fiore, A., Dunbar, R.I.M., Henzi, S.P., Holekamp, K., Korstjens, A.H., Layton, R., Lee, P., Lehmann, J., Manson, J.H., Ramos-Fernandez, G., Strier, K.B. \& Van Schaik, C.P. (2008) Fission-fusion dynamics new research frameworks. Current Anthropology, 49, 627-654.

Barta, Z., Flynn, R. \& Giraldeau, L.A. (1997) Geometry for a selfish foraging group: a genetic algorithm approach. Proceedings of the Royal Society B-Biological Sciences, 264, 1233-1238.

Best, E.C., Dwyer, R.G., Seddon, J.M. \& Goldizen, A.W. (2014) Associations are more strongly correlated with space use than kinship in female eastern grey kangaroos. Animal Behaviour, 89, 1-10.

Biro, D., Sasaki, T. \& Portugal, S.J. (2016) Bringing a time-depth perspective to collective animal behaviour. Trends in Ecology \& Evolution, 31, 550-562.

Bishop, R.P. \& Groves, A.L. (1991) The Social-Structure of Arabian Babbler, TurdoidesSquamiceps, Roosts. Animal Behaviour, 42, 323-325.

Bond, M.L., Lee, D.E., Ozgul, A., Farine, D.R. \& Konig, B. (2021) Leaving by staying: social dispersal in giraffes. Journal of Animal Ecology, 90, 2755-2766.

Brown, D.D., Lapoint, S., Kays, R., Heidrich, W., Kummeth, F. \& Wikelski, M. (2012) Accelerometer-informed GPS telemetry: reducing the trade-off between resolution and longevity. Wildlife Society Bulletin, 36, 139-146.

Cagnacci, F., Boitani, L., Powell, R.A. \& Boyce, M.S. (2010) Animal ecology meets GPSbased radiotelemetry: a perfect storm of opportunities and challenges. Philosophical Transactions of the Royal Society B-Biological Sciences, 365, 21572162.

Cantor, M., Wedekin, L.L., Guimaraes, P.R., Daura-Jorge, F.G., Rossi-Santos, M.R. \& Simoes-Lopes, P.C. (2012) Disentangling social networks from spatiotemporal dynamics: the temporal structure of a dolphin society. Animal Behaviour, 84, 641651.

Chimienti, M., Cornulier, T., Owen, E., Bolton, M., Davies, I.M., Travis, J.M.J. \& Scott, B.E. (2016) The use of an unsupervised learning approach for characterizing latent behaviors in accelerometer data. Ecology and Evolution, 6, 727-741.

Christensen, C., Kern, J.M., Bennitt, E. \& Radford, A.N. (2016) Rival group scent induces changes in dwarf mongoose immediate behavior and subsequent movement. Behavioral Ecology, 27, 1627-1634. 
Christman, M.C. \& Lewis, D. (2005) Spatial distribution of dominant animals within a group: comparison of four statistical tests of location. Animal Behaviour, 70, 73-82.

Connor, R.C. \& Krutzen, M. (2015) Male dolphin alliances in Shark Bay: changing perspectives in a 30-year study. Animal Behaviour, 103, 223-235.

Cortés-Avizanda, A., Jovani, R., Donázar, J.A. \& Grimm, V. (2014) Bird sky networks: how do avian scavengers use social information to find carrion? Ecology, 95, 17991808.

Crofoot, M.C. (2021) "Next-Gen" tracking in primatology: opportunities and challenges. Spatial analysis in field primatology: applying GIS at varying scales (eds F. Dolins, C. Shaffer, L. Porter, J. Hickey \& N. Nibbelink), pp. 42-63. Cambridge University Press, Cambridge.

Crofoot, M.C., Gilby, I.C., Wikelski, M.C. \& Kays, R.W. (2008) Interaction location outweighs the competitive advantage of numerical superiority in Cebus capucinus intergroup contests. Proceedings of the National Academy of Sciences of the United States of America, 105, 577-581.

Davis, G.H., Crofoot, M.C. \& Farine, D.R. (2018) Estimating the robustness and uncertainty of animal social networks using different observational methods. Animal Behaviour, 141, 29-44.

Dehnen, T., Papageorgiou, D., Nyaguthii, B., Cherono, W., Penndorf, J., Boogert, N.J. \& Farine, D.R. (2022) Costs dictate strategic investment in dominance interactions. Philosophical Transactions of the Royal Society B-Biological Sciences, 377.

Dell'Ariccia, G., Dell'Omo, G., Wolfer, D.P. \& Lipp, H.P. (2008) Flock flying improves pigeons' homing: GPS track analysis of individual flyers versus small groups. Animal Behaviour, 76, 1165-1172.

Dewhirst, O.P., Evans, H.K., Roskilly, K., Harvey, R.J., Hubel, T.Y. \& Wilson, A.M. (2016) Improving the accuracy of estimates of animal path and travel distance using GPS drift-corrected dead reckoning. Ecology and Evolution, 6, 6210-6222.

Dyble, M., Houslay, T.M., Manser, M.B. \& Clutton-Brock, T. (2019) Intergroup aggression in meerkats. Proceedings of the Royal Society B-Biological Sciences, 286.

Farine, D.R. (2015) Proximity as a proxy for interactions: issues of scale in social network analysis. Animal Behaviour, 104, E1-E5.

Farine, D.R. (2018) When to choose dynamic vs. static social network analysis. Journal of Animal Ecology, 87, 128-138.

Farine, D.R., Firth, J.A., Aplin, L.M., Crates, R.A., Culina, A., Garroway, C.J., Hinde, C.A., Kidd, L.R., Milligan, N.D., Psorakis, I., Radersma, R., Verhelst, B., Voelkl, B. \& Sheldon, B.C. (2015) The role of social and ecological processes in structuring animal populations: a case study from automated tracking of wild birds. Royal Society Open Science, 2.

Farine, D.R., Strandburg-Peshkin, A., Couzin, I.D., Berger-Wolf, T.Y. \& Crofoot, M.C. (2017) Individual variation in local interaction rules can explain emergent patterns of spatial organization in wild baboons. Proceedings of the Royal Society BBiological Sciences, 284.

Farine, D.R. \& Whitehead, H. (2015) Constructing, conducting and interpreting animal social network analysis. Journal of Animal Ecology, 84, 1144-1163. 
Ferreira, A.C., Silva, L.R., Renna, F., Brandl, H.B., Renoult, J.P., Farine, D.R., Covas, R. \& Doutrelant, C. (2020) Deep learning-based methods for individual recognition in small birds. Methods in Ecology and Evolution, 11, 1072-1085.

Fischer, M., Parkins, K., Maizels, K., Sutherland, D.R., Allan, B.M., Coulson, G. \& Di Stefano, J. (2018) Biotelemetry marches on: A cost-effective GPS device for monitoring terrestrial wildlife. Plos One, 13.

Gall, G.E.C. \& Manser, M.B. (2018) Spatial structure of foraging meerkat groups is affected by both social and ecological factors. Behavioral Ecology and Sociobiology, 72.

Gero, S., Gordon, J. \& Whitehead, H. (2015) Individualized social preferences and longterm social fidelity between social units of sperm whales. Animal Behaviour, 102, 15-23.

Gil, M.A., Hein, A.M., Spiegel, O., Baskett, M.L. \& Sih, A. (2018) Social information links individual behavior to population and community dynamics. Trends in Ecology \& Evolution, 33, 535-548.

Godfrey, S.S., Ansari, T.H., Gardner, M.G., Farine, D.R. \& Bull, C.M. (2014) A contactbased social network of lizards is defined by low genetic relatedness among strongly connected individuals. Animal Behaviour, 97, 35-43.

Gupte, P.R., Beardsworth, C.E., Spiegel, O., Lourie, E., Toledo, S., Nathan, R. \& Bijleveld, A.I. (2021) A Guide to Pre-Processing High-Throughput Animal Tracking Data. $J$ Anim Ecol.

Haddadi, H., King, A.J., Wills, A.P., Fay, D., Lowe, J., Morton, A.J., Hailes, S. \& Wilson, A.M. (2011) Determining association networks in social animals: choosing spatialtemporal criteria and sampling rates. Behavioral Ecology and Sociobiology, 65, 1659-1668.

Hahn, N.R., Wall, J., Denninger-Snyder, K., Goss, M., Sairowua, W., Mbise, N., Estes, A.B., Ndambuki, S., Mjingo, E.E., Douglas-Hamiliton, I. \& Wittemyer, G. (2022) Risk perception and tolerance shape variation in agricultural use for a transboundary elephant population. Journal of Animal Ecology, 91, 112-123.

Harel, R., Loftus, J.C. \& Crofoot, M.C. (2021) Locomotor compromises maintain group cohesion in baboon troops on the move. Proceedings of the Royal Society BBiological Sciences, 288.

He, P., Maldonado-Chaparro, A.A. \& Farine, D.R. (2019) The role of habitat configuration in shaping social structure: a gap in studies of animal social complexity. Behavioral Ecology and Sociobiology, 73.

Henriquez, M.C., Amann, A., Zimmerman, D., Sanchez, C., Murray, S., McCann, C., Tesfaye, T. \& Swedell, L. (2021) Home range, sleeping site use, and band fissioning in hamadryas baboons: Improved estimates using GPS collars. American Journal of Primatology, 83.

Herbert-Read, J.E., Rosen, E., Szorkovszky, A., loannou, C.C., Rogell, B., Perna, A., Ramnarine, I.W., Kotrschal, A., Kolm, N., Krause, J. \& Sumpter, D.J.T. (2017) How predation shapes the social interaction rules of shoaling fish. Proceedings of the Royal Society B-Biological Sciences, 284.

Hirakawa, T., Yamashita, T., Tamaki, T., Fujiyoshi, H., Umezu, Y., Takeuchi, I., Matsumoto, S. \& Yoda, K. (2018) Can Al predict animal movements? Filling gaps in animal trajectories using inverse reinforcement learning. Ecosphere, $\mathbf{9}$. 
Hobson, E.A., Avery, M.L. \& Wright, T.F. (2013) An analytical framework for quantifying and testing patterns of temporal dynamics in social networks. Animal Behaviour, 85, 83-96.

Hoppitt, W.J.E. \& Farine, D.R. (2018) Association indices for quantifying social relationships: how to deal with missing observations of individuals or groups. Animal Behaviour, 136, 227-238.

Hughey, L.F., Hein, A.M., Strandburg-Peshkin, A. \& Jensen, F.H. (2018) Challenges and solutions for studying collective animal behaviour in the wild. Philosophical Transactions of the Royal Society B-Biological Sciences, 373.

Isbell, L.A., Bidner, L.R., Crofoot, M.C., Matsumoto-Oda, A. \& Farine, D.R. (2017) GPSidentified, low-level nocturnal activity of vervets (Chlorocebus pygerythrus) and olive baboons (Papio anubis) in Laikipia, Kenya. American Journal of Physical Anthropology, 164, 203-211.

Jordan, N.R., Cherry, M.I. \& Manser, M.B. (2007) Latrine distribution and patterns of use by wild meerkats: implications for territory and mate defence. Animal Behaviour, 73, 613-622.

Kalnis, P., Mamoulis, N. \& Bakiras, S. (2005) On discovering moving clusters in spatiotemporal data. Advances in Spatial and Temporal Databases, Proceedings, 3633, 364-381.

Kappeler, P.M. (2019) A framework for studying social complexity. Behavioral Ecology and Sociobiology, 73.

Kays, R., Crofoot, M.C., Jetz, W. \& Wikelski, M. (2015) Terrestrial animal tracking as an eye on life and planet. Science, 348.

Keitt, T.H. \& Abelson, E.S. (2021) Ecology in the age of automation. Science, 373, 858859.

Klarevas-Irby, J.A., Wikelski, M. \& Farine, D.R. (2021) Efficient movement strategies mitigate the energetic cost of dispersal. Ecology Letters, 24, 1432-1442.

Klegarth, A., Fuentes, A., Jones-Engel, L., Marshall, G. \& Abernathy, K. (2021) The ethical implications, and practical consequences, of attaching remote telemetry apparatus to Macaques. Spatial analysis in field primatology: applying GIS at varying scales (eds F. Dolins, C. Shaffer, L. Porter, J. Hickey \& N. Nibbelink), pp. 64-86. Cambridge University Press, Cambridge.

Krause, J., James, R., Franks, D.W. \& Croft, D.P. (2015) Animal social networks. Oxford University Press, UK.

Krause, J., Krause, S., Arlinghaus, R., Psorakis, I., Roberts, S. \& Rutz, C. (2013) Reality mining of animal social systems. Trends in Ecology \& Evolution, 28, 541-551.

Leu, S.T., Farine, D.R., Wey, T.W., Sih, A. \& Bull, C.M. (2016) Environment modulates population social structure: experimental evidence from replicated social networks of wild lizards. Animal Behaviour, 111, 23-31.

Linek, N., Volkmer, T., Shipley, J.R., Twining, C.W., Zuniga, D., Wikelski, M. \& Partecke, J. (2021) A songbird adjusts its heart rate and body temperature in response to season and fluctuating daily conditions. Philosophical Transactions of the Royal Society B-Biological Sciences, 376.

Loftus, J.C., Harel, R., Nuñez, C.L. \& Crofoot, M.C. (2021) Ecological and social pressures interfere with homeostatic sleep regulation in the wild. bioRxiv. 
Lührs, M.L. \& Kappeler, P.M. (2013) Simultaneous GPS tracking reveals male associations in a solitary carnivore. Behavioral Ecology and Sociobiology, 67, 1731-1743.

Lukas, D. \& Clutton-Brock, T. (2018) Social complexity and kinship in animal societies. Ecology Letters, 21, 1129-1134.

Marin, F. (2020) Human and Animal Motion Tracking Using Inertial Sensors. Sensors, 20. Nagy, M., Akos, Z., Biro, D. \& Vicsek, T. (2010) Hierarchical group dynamics in pigeon flocks. Nature, 464, 890-U899.

Nomano, F.Y., Browning, L.E., Nakagawa, S., Griffith, S.C. \& Russell, A.F. (2014) Validation of an automated data collection method for quantifying social networks in collective behaviours. Behavioral Ecology and Sociobiology, 68, 1379-1391.

Nyaguthii, B. (2021) Cooperative breeding in the vulturine guineafowl (Acryllium vulturinum) at mpala research center, Laikipia county Kenya. MSc, University of Eldoret.

Papageorgiou, D., Christensen, C., Gall, G.E.C., Klarevas-Irby, J.A., Nyaguthii, B., Couzin, I.D. \& Farine, D.R. (2019) The multilevel society of a small-brained bird. Current Biology, 29, R1120-R1121.

Papageorgiou, D. \& Farine, D.R. (2020a) Group size and composition influence collective movement in a highly social terrestrial bird. Elife, 9.

Papageorgiou, D. \& Farine, D.R. (2020b) Shared decision-making allows subordinates to lead when dominants monopolize resources. Science Advances, 6.

Papageorgiou, D., Rozen-Rechels, D., Nyaguthii, B. \& Farine, D.R. (2021) Seasonality impacts collective movements in a wild group-living bird. Movement Ecology, 9.

Pettit, B., Perna, A., Biro, D. \& Sumpter, D.J.T. (2013) Interaction rules underlying group decisions in homing pigeons. Journal of the Royal Society Interface, 10.

Pinter-Wollman, N., Hobson, E.A., Smith, J.E., Edelman, A.J., Shizuka, D., de Silva, S., Waters, J.S., Prager, S.D., Sasaki, T., Wittemyer, G., Fewell, J. \& McDonald, D.B. (2014) The dynamics of animal social networks: analytical, conceptual, and theoretical advances. Behavioral Ecology, 25, 242-255.

Portugal, S.J. \& White, C.R. (2018) Miniaturization of biologgers is not alleviating the $5 \%$ rule. Methods in Ecology and Evolution, 9, 1662-1666.

Portugal, S.J. \& White, C.R. (2021) Externally attached biologgers cause compensatory body mass loss in birds. Methods in Ecology and Evolution.

Prox, L. \& Farine, D. (2020) A framework for conceptualizing dimensions of social organization in mammals. Ecology and Evolution, 10, 791-807.

Qi, X.G., Garber, P.A., Ji, W.H., Huang, Z.P., Huang, K., Zhang, P., Guo, S.T., Wang, X.W., He, G., Zhang, P. \& Li, B.G. (2014) Satellite telemetry and social modeling offer new insights into the origin of primate multilevel societies. Nature Communications, 5.

Rosenthal, S.B., Twomey, C.R., Hartnett, A.T., Wu, H.S. \& Couzin, I.D. (2015) Revealing the hidden networks of interaction in mobile animal groups allows prediction of complex behavioral contagion. Proceedings of the National Academy of Sciences of the United States of America, 112, 4690-4695.

Rowcliffe, J.M., Carbone, C., Kays, R., Kranstauber, B. \& Jansen, P.A. (2012) Bias in estimating animal travel distance: the effect of sampling frequency. Methods in Ecology and Evolution, 3, 653-662. 
Ryan, P.G., Petersen, S.L., Peters, G. \& Gremillet, D. (2004) GPS tracking a marine predator: the effects of precision, resolution and sampling rate on foraging tracks of African Penguins. Marine Biology, 145, 215-223.

Sankey, D.W.E., Storms, R.F., Musters, R.J., Russell, T.W., Hemelrijk, C.K. \& Portugal, S.J. (2021) Absence of "selfish herd" dynamics in bird flocks under threat. Current Biology, 31, 3192-+.

Sheppard, J.K., McGann, A., Lanzone, M. \& Swaisgood, R.R. (2015) An autonomous GPS geofence alert system to curtail avian fatalities at wind farms. Animal Biotelemetry, 3, 43.

Shizuka, D., Barve, S., Johnson, A.E. \& Walters, E.L. (2021) Constructing social networks from automated telemetry data: a worked example using within- and across-group associations in cooperatively breeding birds. Methods in Ecology and Evolution, n/a.

Shizuka, D. \& Farine, D.R. (2016) Measuring the robustness of network community structure using assortativity. Animal Behaviour, 112, 237-246.

Silk, M.J., Jackson, A.L., Croft, D.P., Colhoun, K. \& Bearhop, S. (2015) The consequences of unidentifiable individuals for the analysis of an animal social network. Animal Behaviour, 104, 1-11.

Smith, J.E. \& Pinter-Wollman, N. (2021) Observing the unwatchable: integrating automated sensing, naturalistic observations and animal social network analysis in the age of big data. Journal of Animal Ecology, 90, 62-75.

Spiegel, O., Leu, S.T., Sih, A. \& Bull, C.M. (2016) Socially interacting or indifferent neighbours? Randomization of movement paths to tease apart social preference and spatial constraints. Methods in Ecology and Evolution, 7, 971-979.

Springer, A., Mellmann, A., Fichtel, C. \& Kappeler, P.M. (2016) Social structure and Escherichia coli sharing in a group-living wild primate, Verreaux's sifaka. Bmc Ecology, 16.

Strandburg-Peshkin, A., Farine, D.R., Couzin, I.D. \& Crofoot, M.C. (2015) Shared decision-making drives collective movement in wild baboons. Science, 348, 13581361.

Strauss, E.D. \& Holekamp, K.E. (2019) Social alliances improve rank and fitness in convention-based societies. Proceedings of the National Academy of Sciences of the United States of America, 116, 8919-8924.

Strauss, E.D., Jensen, F.H., Gersick, A.S., Thomas, M., Holekamp, K.E. \& StrandburgPeshkin, A. (2021) Daily ranging and den usage patterns structure fission-fusion dynamics and social associations in spotted hyenas. bioRxiv, 2021.2010.2001.462772.

Sumpter, D.J.T. (2006) The principles of collective animal behaviour. Philosophical Transactions of the Royal Society B-Biological Sciences, 361, 5-22.

Sunga, J., Webber, Q.M.R. \& Broders, H.G. (2021) Influence of number of individuals and observations per individual on a model of community structure. Plos One, 16.

Thompson, F.J., Marshall, H.H., Vitikainen, E.I.K. \& Cant, M.A. (2017) Causes and consequences of intergroup conflict in cooperative banded mongooses. Animal Behaviour, 126, 31-40. 
Thornton, A., Samson, J. \& Clutton-Brock, T. (2010) Multi-generational persistence of traditions in neighbouring meerkat groups. Proceedings of the Royal Society BBiological Sciences, 277, 3623-3629.

Tomkiewicz, S.M., Fuller, M.R., Kie, J.G. \& Bates, K.K. (2010) Global positioning system and associated technologies in animal behaviour and ecological research. Philosophical Transactions of the Royal Society B-Biological Sciences, 365, 21632176.

Wang, G.M. (2019) Machine learning for inferring animal behavior from location and movement data. Ecological Informatics, 49, 69-76.

Wensveen, P.J., Thomas, L. \& Miller, P.J.O. (2015) A path reconstruction method integrating dead-reckoning and position fixes applied to humpback whales. Movement Ecology, 3.

Whetten, A.B. (2021) Smoothing splines of apex predator movement: Functional modeling strategies for exploring animal behavior and social interactions. Ecology and Evolution, n/a.

Whitehead, H. (2008) Analyzing animal societies: quantitative methods for vertebrate social analysis. University of Chicago Press.

Wielgus, E., Caron, A., Bennitt, E., De Garine-Wichatitsky, M., Cain, B., Fritz, H., Miguel, E., Cornelis, D. \& Chamaille-Jammes, S. (2021) Inter-group social behavior, contact patterns and risk for pathogen transmission in Cape buffalo populations. Journal of Wildlife Management, 85, 1574-1590.

Wild, S. \& Hoppitt, W. (2019) Choosing a sensible cut-off point: assessing the impact of uncertainty in a social network on the performance of NBDA. Primates, 60, 307315.

Williams, H.J., Taylor, L.A., Benhamou, S., Bijleveld, A.I., Clay, T.A., de Grissac, S., Demsar, U., English, H.M., Franconi, N., Gomez-Laich, A., Griffiths, R.C., Kay, W.P., Morales, J.M., Potts, J.R., Rogerson, K.F., Rutz, C., Spelt, A., Trevail, A.M., Wilson, R.P. \& Borger, L. (2020) Optimizing the use of biologgers for movement ecology research. Journal of Animal Ecology, 89, 186-206.

Wilmers, C.C., Nickel, B., Bryce, C.M., Smith, J.A., Wheat, R.E. \& Yovovich, V. (2015) The golden age of bio-logging: how animal-borne sensors are advancing the frontiers of ecology. Ecology, 96, 1741-1753.

Wilson, E.O. (1975) Sociobiology: the new synthesis. Belknap Press, Cambridge, MA.

Wilson, R.P., Rose, K.A., Gunner, R., Holton, M.D., Marks, N.J., Bennett, N.C., Bell, S.H., Twining, J.P., Hesketh, J., Duarte, C.M., Bezodis, N., Jezek, M., Painter, M., Silovsky, V., Crofoot, M.C., Harel, R., Arnould, J.P.Y., Allan, B.M., Whisson, D.A., Alagaili, A. \& Scantlebury, D.M. (2021) Animal lifestyle affects acceptable mass limits for attached tags. Proceedings of the Royal Society B-Biological Sciences, 288.

Wittemyer, G., Polansky, L., Douglas-Hamilton, I. \& Getz, W.M. (2008) Disentangling the effects of forage, social rank, and risk on movement autocorrelation of elephants using Fourier and wavelet analyses. Proceedings of the National Academy of Sciences of the United States of America, 105, 19108-19113. 

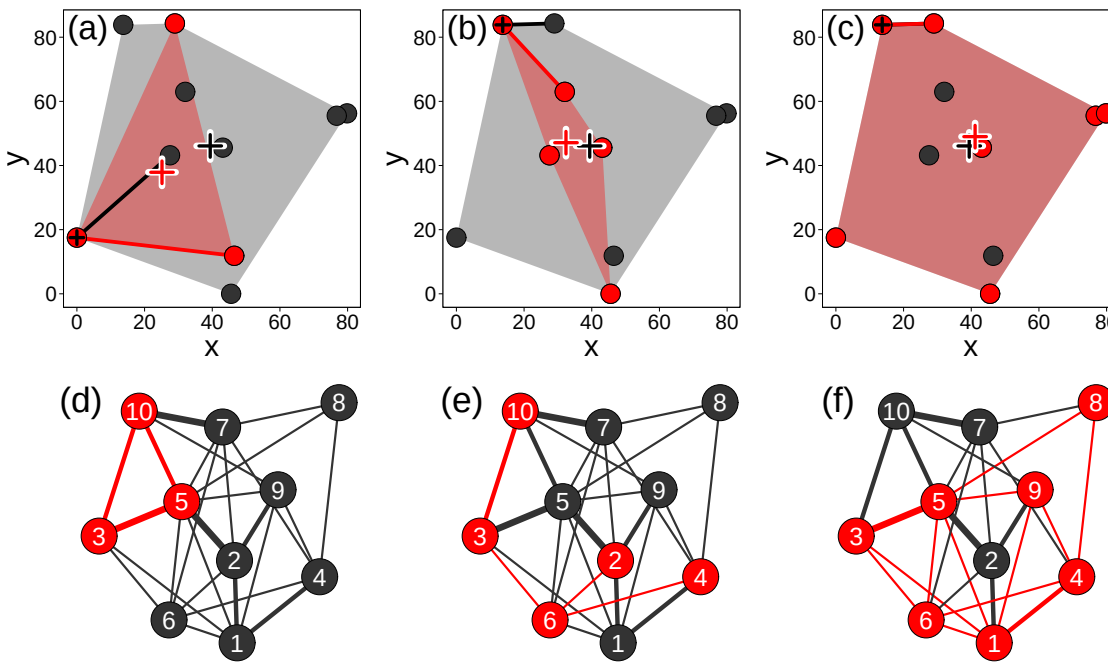
